\title{
Análise econômica da adição de níveis crescentes de concentrado em dietas para vacas leiteiras mestiças alimentadas com cana-de-açúcar ${ }^{1}$
}

\section{Lucas Teixeira Costa ${ }^{2}$, Fabiano Ferreira da Silva ${ }^{3}$, Cristina Mattos Veloso ${ }^{4}$, Aureliano José Vieira Pires ${ }^{3}$, Aires Lima Rocha Neto ${ }^{2}$, Fabrício Bacelar Lima Mendes ${ }^{2}$, Eli Santana de Oliveira Rodrigues ${ }^{5}$, Vinicius Lopes da Silva ${ }^{2}$}

\author{
1 Projeto financiada pelo Banco do Nordeste. \\ 2 Doutorando do Programa de Pós-graduação em Zootecnia - UESB/Itapetinga. \\ ${ }^{3}$ UESB/ltapetinga. Bolsista do CNPq. \\ ${ }^{4}$ UFV/Viçosa. Bolsista do CNPq. \\ ${ }^{5}$ Graduando em Zootecnia - UESB/Itapetinga.
}

RESUMO - Dezesseis vacas mestiças Holandês $\times$ Zebu (grau de sangue variando de $1 / 2$ a $3 / 4$ Holandês $\times$ Zebu) foram distribuídas segundo quatro quadrados latinos $4 \times 4$ para se avaliar a viabilidade econômica do aumento do nível de concentrado na dieta. As vacas de terceira ou quarta lactação, com produção anterior entre 2.500 e $3.000 \mathrm{~kg}$, ajustada para 300 dias, foram manejados a pasto na época das águas, e com 110 dias de lactação no início do período experimental. Com os preços do leite e concentrado praticados no momento do estudo, não é interessante a utilização de concentrado na dieta de vacas leiteiras alimentadas com cana-de-açúcar. Contudo, considerando os aspectos produtivo e econômico conjuntamente, e os preços de R\$ 0,70 e R\$ 0,50 para o leite e o concentrado, respectivamente, a utilização de $24 \%$ de concentrado na dieta é a opção mais interessante para vacas leiteiras alimentadas com cana-de-açúcar.

Palavras-chave: concentrado, custos, leite, preço, produtivo, sistemas de produção

\section{Economical analysis of different concentrate levels for dairy crossbred fed sugar cane based diets}

\begin{abstract}
Sixteen crossbred Holstein $\times$ Zebu cows (groups from $1 / 2$ to $3 / 4$ of Holstein $\times$ Zebu) at third of fourth lactation were allotted to four $4 \times 4$ Latin squares to evaluate the economical viability of increasing dietary concentrate level. Cows presented previous milk yield from 2,500 to 3,000 kg, adjusted for 300 days, and grazed pasture during the rainy season, and with 110 days of laction in the beginning of the experimental period. Because of the prices of milk and concentrate during the experiment, it is not interesting to use concentrate in the diets of milk cows fed sugar cane. If the productive and economical aspects toghther and the prices of $\mathrm{R} \$ 0.70$ and $\mathrm{R} \$ 0.50$ for the milk and the concentrate, respectively are considered, the use of $24 \%$ concentrate in the diet is the most interesting option for dairy cows fed sugar cane.
\end{abstract}

Key Words: concentrated, costs, milk, price, productive, systems of production

\section{Introdução}

Os custos de produção, a receita obtida e a rentabilidade do capital investido são fatores importantes para o sucesso de qualquer sistema de produção. Essa análise permite a detecção do item que, em determinado momento, pode inviabilizar a atividade, como as oscilações de preços no mercado (Peres et al., 2004).

Na composição do custo de alimentação, não só os alimentos concentrados, mas também os volumosos, têm participação importante, pois representam 40 a $80 \%$ da matéria seca (MS) da dieta das várias categorias que compõem o rebanho leiteiro.
De acordo com Gomes (2000a), o fornecimento de concentrado em quantidade fixa pode subalimentar as vacas mais produtivas, determinando prejuízos para a produção de leite, e superalimentar as menos produtivas, elevando os custos dos sistemas de produção. A avaliação da economicidade no uso de concentrados está diretamente relacionada à qualidade do volumoso e ao potencial genético dos animais.

Em rebanhos com maior produtividade, o custo de dieta por animal é mais elevado, mas a produção também maior costuma compensar o investimento. Quando se analisa o custo final da dieta por litro, vacas mais produtivas mostram-se mais rentáveis, visto que o custo por litro é menor (CEPEA, 2007). 
Segundo Peres et al. (2004), alguns indicadores econômicos podem ser adotados para a avaliação financeira de sistemas de produção, entre eles, o valor presente líquido (VPL) e a taxa interna de retorno (TIR). O valor presente líquido é considerado um critério rigoroso de avaliação de projetos e isento de falhas técnicas (Noronha, 1987; Contador, 1988). Corresponde à soma algébrica dos valores do fluxo de caixa de um projeto, atualizados à taxa ou às taxas de desconto do período em questão. Segundo esse indicador, um projeto é viável se apresentar valor presente líquido positivo. Na implantação do melhor projeto, escolher-se-á aquele com maior valor presente líquido positivo. A taxa interna de retorno (TIR) é definida por Contador (1988) como a taxa de juros que iguala a zero o valor presente líquido de um projeto, ou seja, é a taxa de desconto que iguala o valor presente dos benefícios de um projeto ao valor presente de seus custos. Um projeto é viável e deve ser adotado quando sua TIR é igual ou maior que o custo de oportunidade dos recursos para sua implantação.

Este trabalho foi realizado com o objetivo de verificar o desempenho e a viabilidade econômica do uso de diferentes níveis de concentrado na dieta de vacas leiteiras alimentadas com cana-de-açúcar.

\section{Material e Métodos}

O experimento foi conduzido no período de julho a setembro de 2006 utilizando-se 16 vacas mestiças Holandês $\times$ Gir (grau de sangue variando de $1 / 2$ a $3 / 4$ de sangue Holandês $\times$ Gir), de terceira ou quarta lactação, com produção anterior entre 2.500 e $3.000 \mathrm{~kg}$, ajustada para 300 dias, manejadas a pasto na época das águas, e com 110 dias, em média, de lactação no início do período experimental, com o escore corporal de 2,5 a 3 na escala de 1 a 5 .

Foram avaliados diferentes níveis de suplementação concentrada, tendo como volumoso a cana-de-açúcar (Saccharum officinarum) da variedade RB 72-454, colhida em um canavial de quatro anos de plantado cortado anualmente, com produtividade média de 90 t.ha ${ }^{-1}$.ano ${ }^{-1}$, tratada com $1 \%$ de uma mistura de ureia e sulfato de amônia (9:1 partes) durante toda a fase experimental. Houve um período preliminar de adaptação de uma semana para todos os animais utilizando-se apenas $0,5 \%$ desta mistura. Os níveis de suplementação concentrada foram definidos pelo balanceamento das dietas para conter nutrientes suficientes para mantença e produção de 6, 9, 12 e $15 \mathrm{~kg}$ dia $^{-1}$ de leite (Tabela 1), de acordo com o NRC (2001) e com base nos dados da análise bromatológica da cana-de-açúcar (Tabela 2) previamente realizada no início do período de adaptação. O teor de nutrientes digestíveis totais (NDT) da cana foi estimado a partir da equação de regressão NDT $=74,49-$ $0,5635 *$ FDA $\left(r^{2}=0,84\right)$, descrita por Cappelle et al. (2001) para volumosos.

A relação volumoso:concentrado foi de 100:0; 84:16; 76:24 e 70:30, com base na MS, para as dietas formuladas para produções estimadas de 6, 9, 12 e 15 kg de leite.dia ${ }^{-1}$, respectivamente.

As 16 vacas lactantes foram distribuídas em quatro quadrados latinos $4 \times 4$, num experimento constituído de quatro períodos experimentais de 17 dias. Os primeiros dez dias de cada período foram considerados de adaptação e os sete restantes para coleta de dados, conforme recomendado por Oliveira et al. (2001).

Os animais foram alojados em baias individuais de $4 \mathrm{~m}^{2}$, providas de cochos individuais e bebedouros automáticos. O alimento foi oferecido na forma de mistura completa, duas vezes ao dia, às 6 e às 15 h, à vontade, de modo a permitir 5 a $10 \%$ de sobras.

A produção de leite foi avaliada do $10^{\circ}$ ao 170 dia de cada período experimental. A produção de leite corrigida (PLC) para 3,5\% de gordura foi estimada segundo Sklan et al. (1992), pela seguinte equação: $\mathrm{PLC}=(0,432+0,1625 \times \%$ gordura do leite) $\times$ produção de leite em kg.dia ${ }^{-1}$.

Do $10^{\underline{0}}$ ao $17^{0}$ dia de cada período experimental, o alimento oferecido e as sobras foram pesados para estimativa de consumo. Os animais foram pesados no início do experimento e ao final de cada período, para verificação da variação do peso corporal de cada tratamento.

As análises de matéria seca (MS), proteína bruta (PB), extrato etéreo (EE), fibra em detergente neutro (FDN), fibra em detergente ácido (FDA), carboidratos não-fibrosos (CNF), proteína insolúvel em detergente neutro (PIDN), proteína insolúvel em detergente ácido (PIDA), lignina e matéria mineral (MM) das dietas (Tabela 3) foram realizadas conforme Silva \& Queiroz (2002).

Os valores da composição da cana de açúcar são semelhantes aos reportados por Valadares Filho (2002), com pequenas variações em relação aos teores de FDN e

Tabela 1 - Composição dos concentrados, em porcentagem da matéria natural

\begin{tabular}{lccc}
\hline Ingrediente & \multicolumn{3}{c}{ Produção de leite $\left(\mathrm{kg.dia}^{-1}\right)$} \\
\cline { 2 - 4 } & 9 & 12 & 15 \\
\hline Calcário calcítico (\%) & 0,60 & 0,83 & 0,18 \\
Farelo de soja (\%) & 19,15 & 23,98 & 21,44 \\
Fosfato bicálcico (\%) & 7,49 & 4,93 & 3,94 \\
Fubá de milho (\%) & 66,64 & 65,56 & 70,32 \\
Sal mineral ${ }^{1}$ (\%) & 6,12 & 4,70 & 4,12 \\
\hline${ }^{1}$ Composição: cálcio - 18,5\%; fósforo - 9\%; magnésio - 0,4\%; enxofre - 1\%; sódio - \\
11,7\%; selênio - 30 ppm; cobre - 1.500 ppm; zinco - 4.000 ppm; manganês - \\
1.200 ppm; iodo - 150 ppm; cobalto - 150 ppm.
\end{tabular}

R. Bras. Zootec., v.40, n.5, p.1155-1162, 2011 
Tabela 2 - Composição química (em porcentagem) da cana-de-açúcar e dos concentrados

\begin{tabular}{|c|c|c|c|c|c|c|c|c|}
\hline \multirow[t]{2}{*}{ Item } & \multirow{2}{*}{$\begin{array}{c}\text { Cana de açúcar } \\
+ \text { ureia }\end{array}$} & \multirow[t]{2}{*}{ Erro-padrão } & \multicolumn{6}{|c|}{ Produção de leite $\left(\mathrm{kg} \mathrm{dia}^{-1}\right)$} \\
\hline & & & 9 & Erro-padrão & 12 & Erro-padrão & 15 & Erro-padrão \\
\hline Matéria seca & 27,2 & 0,7 & 86,3 & 0,2 & 87,0 & 0,4 & 87,1 & 0,5 \\
\hline Extrato etéreo (\% MS) & 1,8 & 0,2 & 3,4 & 0,2 & 3,6 & 0,1 & 3,6 & 0,1 \\
\hline Fibra em detergente neutro (\% MS) & 59,4 & 0,8 & 38,4 & 1,0 & 35,8 & 0,3 & 34,9 & 0,7 \\
\hline Fibra em detergente ácido (\% MS) & 39,9 & 0,6 & 11,4 & 0,5 & 8,2 & 0,2 & 10,6 & 0,4 \\
\hline PIDA (\% proteína total) & 1,5 & 0,1 & 7,4 & 0,3 & 7,4 & 0,3 & 6,4 & 0,4 \\
\hline Lignina (\% MS) & 6,9 & 0,1 & 2,8 & 0,1 & 2,9 & 0,1 & 3,0 & 0,0 \\
\hline Matéria mineral (\% MS) & 4,4 & 0,2 & 8,4 & 0,7 & 7,7 & 0,5 & 7,4 & 0,6 \\
\hline
\end{tabular}

PIDN - proteína insolúvel em detergente neutro, PIDA - proteína insolúvel em detergente ácido.

FDA. O canavial onde foi colhida a cana-de-açúcar tem produtividade média de 90 toneladas.ha ${ }^{-1}$ e foi estabelecido há quatro anos; nele, as colheitas são feitas anualmente e capina mecânica duas a três vezes ao ano.

As informações necessárias para elaboração deste trabalho e composição dos custos, bem como os dados utilizados (preços, vida útil etc.), foram coletadas junto aos produtores rurais, técnicos de extensão rural e estabelecimentos comerciais da região. A quantidade de terra utilizada para o plantio de cana-de-açúcar foi calculada pela média de consumo dos animais e produção da mesma da propriedade utilizada. Embutidos no preço da MS da cana-de-açúcar estão os gastos com implantação, manutenção e recuperação do canavial (Tabela 4).

Tabela 3 - Composição química das dietas (\%)

\begin{tabular}{lcccc}
\hline Item & \multicolumn{4}{c}{ Nível } \\
\cline { 2 - 5 } & 0 & 16 & 24 & 30 \\
\hline Materia seca & 27,2 & 36,7 & 41,6 & 45,2 \\
Proteína bruta (\% MS) & 8,2 & 9,6 & 10,4 & 10,8 \\
Extrato etéreo (\% MS) & 1,8 & 2,1 & 2,3 & 2,4 \\
Fibra em detergente neutro (\% MS) & 59,4 & 56,1 & 53,8 & 52,1 \\
Fibra em detergente ácido (\% MS) & 39,9 & 35,3 & 31,3 & 31,1 \\
Carboidratos não-fibrosos (\% MS) & 29,0 & 29,8 & 31,1 & 31,9 \\
PIDN & 2,1 & 3,4 & 4,0 & 5,1 \\
PIDA & 1,5 & 2,4 & 2,9 & 3,0 \\
Lignina (\% MS) & 6,9 & 6,2 & 5,9 & 5,7 \\
Materia mineral (\% MS) & 4,4 & 5,0 & 5,2 & 5,3 \\
Nutrientes digestíveis totais & 53,11 & 53,05 & 53,23 & 56,15 \\
\hline PIDN - proteína insolúvel em detergente neutro; PIDA - proteína insolúvel em \\
detergente ácido; NDT - nutrientes digestíveis totais.
\end{tabular}

Foram consideradas, para avaliação do custo de produção (Tabelas 5 e 6), as metodologias de custo operacionais utilizadas pelo IPEA (Matsunaga et al., 1976, citados por Rodrigues Filho, 2002). Para produção de esterco, utilizou-se a produção fecal calculada pela fração indigestível da MS na ração total, FDNi obtida a partir de incubação em bovinos fistulados.

A depreciação de benfeitorias, máquinas, equipamentos e animais de serviço foi estimada pelo método linear de cotas fixas, com valor final igual a zero, com exceção dos animais (Tabela 7). Para remuneração do capital, utilizou-se a taxa de juros real de $6 \%$ ao ano.

Utilizaram-se, para efeito de estudo da análise econômica, dois indicadores econômicos: o VPL (valor presente líquido) e a TIR (taxa interna de retorno). A expressão para cálculo do VPL é a seguinte:

$$
\mathrm{VPL}=\sum_{\mathrm{t}=0}^{\mathrm{n}=\mathrm{i}} \mathrm{VF} /(1+\mathrm{r})^{\mathrm{t}}
$$

em que VPL = valor presente líquido; VF = valor do fluxo líquido (diferença entre entradas e saídas); $\mathrm{n}$ = número de fluxos; $\mathrm{r}$ = taxa de desconto; $\mathrm{t}$ = período de análise $(\mathrm{i}=1,2$, 3...). No cálculo do valor presente líquido, aplicaram-se três taxas de desconto sobre o fluxo líquido mensal de cada sistema de produção. As taxas adotadas foram 6, 10 e 12\% ao ano.

Para a taxa interna de retorno, segundo os critérios de aceitação, quanto maior o resultado obtido no projeto, maior a atratividade para sua implantação. Assim, a taxa

Tabela 4 - Custo da cana-de-açúcar

\begin{tabular}{lcc}
\hline Operação & Custo (\$) & Produtividade do canavial, em MS \\
\hline Plantio $^{1}$ & 3000,00 & 22500 \\
Adubação de manutenção & 500,00 & \\
Capina & 500,00 & \\
Colheita & 500,00 & \\
Total & 4500,00 & \\
\hline
\end{tabular}

${ }^{1}$ Incluindo mudas, mão-de-obra e adubação de plantio. 
interna de retorno é o valor de $\mathrm{r}$ que iguala a zero a expressão:

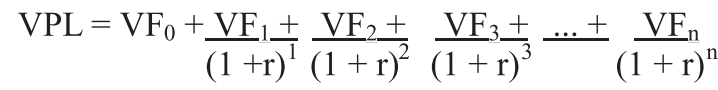

em que VF = fluxos de caixa líquido $(0,1,2,3, \ldots, n) ; r=$ taxa de desconto.

Para cálculo da taxa interna de retorno e do valor presente líquido, fez-se uma simulação de um ano para estudo de características econômicas, sendo computada, assim, a depreciação de benfeitorias e máquinas neste período (Tabela 7).

Os dados de consumo de MS total, do concentrado e da cana-de-açúcar, produção de leite e variação do peso corporal foram avaliados por meio de análises de variância e de regressão, utilizando-se o Sistema de Análises Estatísticas e Genéticas - SAEG (Ribeiro Júnior, 2001). Os modelos estatísticos foram escolhidos de acordo com a significância dos coeficientes de regressão, utilizando-se o teste " $\mathrm{t}$ " no

Tabela 5 - Preço médio de venda dos produtos no período experimental

\begin{tabular}{lcc}
\hline Produto & Unidade & Valor \\
\hline Leite & litros $(\mathrm{L})$ & $0,70^{1}$ \\
Esterco & toneladas (t) & $40,00^{2}$ \\
\hline
\end{tabular}

${ }^{1}$ Vendido pela propriedade na época do experimento para empresa Vale Dourado.

${ }^{2}$ Comprado de proprietários vizinhos.

Tabela 6 - Preços de insumos e serviços utilizados no experimento

\begin{tabular}{lcc}
\hline Discriminação & Unidade & Preço unitário (R\$) \\
\hline Concentrado básico & $\mathrm{kg}$ de MS & 0,50 \\
Cana-de-açúcar & $\mathrm{kg}$ de MS & 0,20 \\
Vermífugo & $\mathrm{mL}$ & 0,06 \\
Carrapaticida & $\mathrm{mL}$ & 0,09 \\
Vacina de aftosa & Dose & 1,00 \\
Mão-de-obra & Dias/homem & 18,00 \\
Outros medicamentos* & $\mathrm{mL}$ & 0,15 \\
\hline
\end{tabular}

Média de preços de alguns medicamentos que foram eventualmente utilizados. Dados coletados em pontos comerciais da região. nível de 5\%, e de determinação $\left(\mathrm{R}^{2}\right)$, e com o fenômeno biológico estudado.

\section{Resultados e Discussão}

Os níveis de FDN do concentrado são considerados altos, 38,4; 35,8 e 34,9\%, o que pode ser atribuído a uma possível contaminação do milho por sabugo, pois o fubá é de fácil contaminação por esta parte da planta, que possui alto teor de fibra.

Houve efeito linear $(\mathrm{P}<0,05)$ dos tratamentos sobre 0 consumo de MS, que aumentou 0,33 kg a cada unidade de concentrado, chegando a ser $133 \%$ de aumento no último nível (Tabela 8). Mendonça et al. (2004) observaram consumo $9,6 \%$ maior para a dieta com $50 \%$ de concentrado em relação àquela com 40 e $1 \%$ de ureia e o consumo da dieta com $60 \%$ de cana foi 11,2 e $25,6 \%$ menor que o observado com fornecimento das dietas com 50 e $40 \%$ de concentrado. Cordeiro et al. (2007), trabalhando com diferentes níveis de proteína na dieta de vacas leiteiras, também observaram aumento do consumo de MS com o aumento de proteína na dieta.

O aumento do nível de concentrado na dieta favoreceu o maior consumo de MS e nutrientes, o que pode ser explicado pela menor quantidade proporcional de FDN ingerida em relação ao acréscimo do consumo de MS. O consumo de concentrado também apresentou comportamento linear $(\mathrm{P}<0,05)$, o que pode ser uma consequência do aumento, também linear, do consumo de MS.

O consumo de cana-de-açúcar apresentou comportamento quadrático, com ponto de máximo com 26,6\% de concentrado na dieta e valor igual a 12,04 kg de cana-deaçúcar. Isso pode ser explicado pelo alto teor de FDN da cana-de-açúcar, que pode ter limitado seu consumo, tendo em vista os dados de consumo de FDN por peso corporal (PC),

Tabela 7 - Vida útil e valor de benfeitorias, máquinas, equipamentos, animais e terra, quantidades utilizadas no experimento e o seu valor total

\begin{tabular}{|c|c|c|c|c|}
\hline Discriminação & Vida útil (anos) & Valor unitário (R\$) & Quantidade utilizada (unidade) & Valor total (R\$) \\
\hline Balança de curral - 1500 kg & 15 & 2640,00 & 1 & $2.640,00$ \\
\hline Balança para pesagem de leite & 10 & 250,00 & 1 & 250,00 \\
\hline Máquina de ração estacionária & 15 & 3500,00 & 1 & $3.500,00$ \\
\hline Pulverizador costal & 10 & 110,00 & 1 & 110,00 \\
\hline Facão para cana & 2 & 20,00 & 1 & 20,00 \\
\hline Pá de bico & 2 & 22,00 & 1 & 22,00 \\
\hline Carrinho de mão & 2 & 75,00 & 1 & 75,00 \\
\hline Garfo de quatro dentes & 2 & 22,00 & 1 & 22,00 \\
\hline Unidades de pequeno valor & 2 & 40,00 & 1 & 40,00 \\
\hline Galpão de confinamento & 20 & 8000,00 & 1 & $8.000,00$ \\
\hline Vacas & 8 & 1500,00 & 16 & $24.000,00$ \\
\hline Terra nua & & 4000,00 & 4 & $16.000,00$ \\
\hline Valor fixo investido & & & & $54.679,00$ \\
\hline
\end{tabular}

Dados coletados em pontos comerciais da região. 
Tabela 8 - Consumos de concentrado e cana-de-açúcar, consumos de matéria seca, fibra em detergente neutro e proteína bruta e produtividade do rebanho obtida com o acréscimo de concentrado na dieta

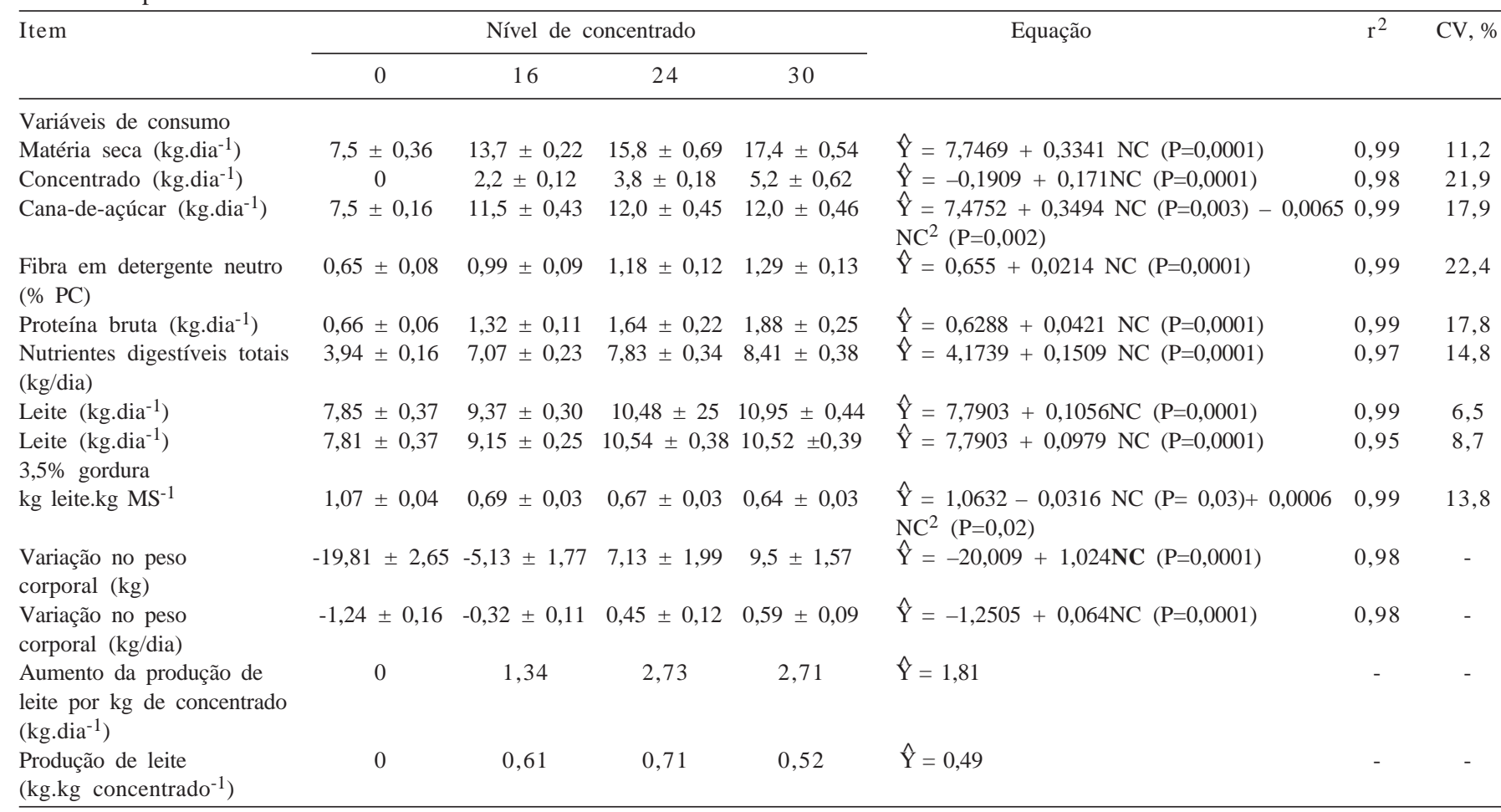

pois, segundo Mertens (1985), o consumo de MS de ruminantes é ótimo quando o consumo de FDN alcança 1,2 + 0,1\% do peso corporal de vacas leiteiras. Os resultados encontrados neste trabalho, quanto ao consumo de FDN em relação ao peso corporal, foram 0,65; 0,99; 1,18 e 1,29 para 0, 16, 24 e 30\% de concentrado, respectivamente. Assim, pode-se inferir que o consumo foi limitado pelo teor de FDN nas dietas.

Os valores de consumo de PB e NDT recomendados pelo NRC (2001) para vacas com produção média diária de 6, 9, 12 e 15 kg de leite.dia-1 são de 0,97; 1,22; 1,47 e 1,63 kg de PB.dia-1 e 5,48; 6,22; 7,11 e 8,00 kg de NDT.dia-1, respectivamente. No entanto, os valores obtidos com as dietas experimentais foram: 0,63; 1,39; 1,68 e 1,93 kg de PB.dia-1 e 3,94; 7,07; 7,83 e 8,41 kg de NDT.dia-1 e isso indica que as exigências não foram atendidas por algumas das dietas, enquanto com outras houve consumo excessivo de nutrientes. Além disso, o NRC (2001) não foi interessante como base de decisão para formulação de ração para esses animais nessas condições e com esse padrão genético.

A produção de leite e a produção de leite corrigida para $3,5 \%$ de gordura apresentaram comportamento linear ( $\mathrm{P}<0,05)$, com acréscimo de 0,1056 e 0,0979 para cada unidade de concentrado, chegando a valores 34 e 34,6\% maiores para o último nível de concentrado, respectivamente (Figura 1).

A menor produção de leite nas dietas com maior participação de cana-de-açúcar pode ser explicada pelo menor consumo de MS, que resultou em menor consumo de nutrientes. Isso pode ser mais bem evidenciado se comparados a produção de leite e o consumo de MS da dieta com 30\% de concentrado com as demais. Resultados semelhantes foram encontrados por Mendonça et al. (2004) e Costa et al. (2005), em pesquisa com diferentes níveis de concentrado na dieta. Este efeito apoia a teoria proposta pelo NRC (2001), que considera ocorrer resposta linear da produção de leite com o suprimento de energia e proteína (Gráfico 1).

Os níveis de concentrado tiveram efeito quadrático $(\mathrm{P}<0,05)$ sobre a eficiência alimentar ( $\mathrm{kg}$ de leite/kg de MS), provavelmente porque os animais não converteram o alimento em leite, mas sim em gordura, aumentando o peso corporal, como mostra a variação do peso vivo, o que

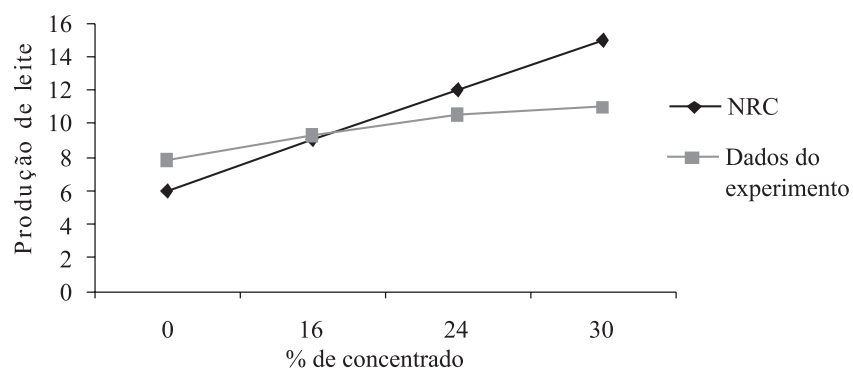

Figura 1 - Produção de leite por \% de concentrado na dieta. 
explica também a resposta não esperada de produção de leite, de 7,85; 9,37; 10,48 e 10,95 kg de leite.dia ${ }^{-1}$, enquanto a esperada seria de 6; 9; 12 e 15 kg de leite.dia ${ }^{-1}$, mostrando que os animais escolhidos não possuíam potencial genético para essas produções.

O ganho de peso corporal apresentou comportamento linear ( $\mathrm{P}<0,05)$, aumentando 1,0246 e 0,064 por unidade de concentrado, quando analisado no período experimental e diariamente, respectivamente. Isso demonstra que os animais não tinham potencial genético para expressar a produção esperada e converteram o alimento em gordura. Ressalta-se que os animais perderam peso quando fornecidas as dietas com 0 e $16 \%$ de concentrado. Isso provavelmente acarretaria problemas reprodutivos, os quais não foram encontrados neste trabalho, devido à pequena duração do mesmo.

A produção de leite aumentou $(\mathrm{P}<0,05)$ quando se acrescentou concentrado à dieta, porém, outro fator importante é a produção de leite por quilo de concentrado, que reduziu nesta proporção (Tabela 8). Isso indica que uma parte desse concentrado não está sendo utilizada para produção de leite. Com esse parâmetro, pode-se chegar a uma equação para saber qual nível de concentrado será mais interessante em um devido momento, sendo esta igual a:

$\mathrm{PMC}=$ plc $\times \mathrm{PL}$

em que $\mathrm{PMC}=$ preço máximo do concentrado, plc = produção de leite por quilo de concentrado e $\mathrm{PL}=$ preço de leite.

Com esta equação, o produtor poderá se abster das oscilações de mercado, tanto para o preço do leite quanto para o preço do concentrado, que são os mais representativos parâmetros para o cálculo de viabilidade econômica desses sistemas de produção, um outro parâmetro de muita importância, a resposta do animal, é também contemplada por esta equação.

Tabela 9 - Renda bruta, custo operacional efetivo, custo operacional total, custo total, lucro por vaca por dia

\begin{tabular}{|c|c|c|c|c|c|c|c|c|c|}
\hline \multirow{3}{*}{ I } & \multirow{3}{*}{$\begin{array}{c}\text { Preço (R\$) } \\
\text { unitário }\end{array}$} & \multicolumn{8}{|c|}{ Nível de concentrado (\%) } \\
\hline & & \multicolumn{2}{|c|}{0} & \multicolumn{2}{|c|}{16} & \multicolumn{2}{|c|}{24} & \multicolumn{2}{|c|}{30} \\
\hline & & Quantida & Valor & Quantidade & Valor & Quantidade & Valor & Quantidade & Valor \\
\hline Venda de leite, kg & 0,70 & 7,85 & 5,50 & 9,37 & 6,56 & 10,48 & 7,34 & 10,95 & 7,67 \\
\hline Venda de esterco, kg & 0,04 & 16,17 & 0,57 & 31,53 & 1,10 & 36,11 & 1,26 & 39,47 & 1,38 \\
\hline Total & & & 6,06 & & 7,66 & & 8,60 & & 9,05 \\
\hline Mão-de-obra, dias/homem & 18,00 & 0,06 & 1,13 & 0,06 & 1,13 & 0,06 & 1,13 & 0,06 & 1,13 \\
\hline Concentrado, kg & $0,51 *$ & 0,00 & 0,00 & 2,19 & 1,16 & 3,78 & 1,89 & 5,23 & 2,51 \\
\hline Cana-de-açúcar, kg & 0,20 & 7,46 & 1,49 & 11,51 & 2,30 & 11,99 & 2,40 & 12,21 & 2,44 \\
\hline Medicamentos & & & 0,05 & & 0,05 & & 0,05 & & 0,05 \\
\hline Energia, KW/h & 0,27 & 0,86 & 0,23 & 0,86 & 0,23 & 0,86 & 0,23 & 0,86 & 0,23 \\
\hline Reparo de benfeitorias, R\$ & & & 0,60 & & 0,60 & & 0,60 & & 0,60 \\
\hline Depreciação de benfeitorias, $\mathrm{R}$ & & & 0,09 & & 0,09 & & 0,09 & & 0,09 \\
\hline Depreciação de máquinas, $\mathrm{R} \$$ & & & 0,11 & & 0,11 & & 0,11 & & 0,11 \\
\hline Depreciação das vacas, R\$ & & & 0,55 & & 0,55 & & 0,55 & & 0,55 \\
\hline Subtotal & & & 4,29 & & 6,22 & & 7,09 & & 7,75 \\
\hline \multicolumn{10}{|c|}{ Custo total, R\$ } \\
\hline Custo operacional total, $\mathrm{R} \$$ & & & 4,29 & & 6,22 & & 7,09 & & 7,75 \\
\hline Juros benfeitoria, R\$ & & & 0,12 & & 0,12 & & 0,12 & & 0,12 \\
\hline Juros sobre máquinas, $\mathrm{R} \$$ & & & 0,07 & & 0,07 & & 0,07 & & 0,07 \\
\hline Custo total/animal, $\mathrm{R} \$$ & & & 4,48 & & 6,41 & & 7,28 & & 7,94 \\
\hline Custo/litro de leite, $\mathrm{R} \$$ & & & 0,57 & & 0,68 & & 0,69 & & 0,72 \\
\hline Margem bruta/animal, $\mathrm{R} \$ *$ & & & 2,52 & & 2,14 & & 2,26 & & 2,04 \\
\hline Margem líquida/animal, $\mathrm{R} \$ * *$ & & & 1,77 & & 1,44 & & 1,51 & & 1,30 \\
\hline
\end{tabular}

* Renda bruta - custo operacional efetivo; ** Renda bruta - custo operacional total; ** Renda bruta - custo total. 
Tabela 10 - Taxa interna de retorno mensal e valor presente líquido para taxas de retorno de 6, 10 e $12 \%$, respectivamente, para um ano

\begin{tabular}{|c|c|c|c|c|}
\hline \multirow[t]{2}{*}{ Item } & \multicolumn{4}{|c|}{ Nível de concentrado (\%) } \\
\hline & 0 & 16 & 24 & 30 \\
\hline Taxa interna de retorno (\%) & 1,94 & 1,63 & 1,72 & 1,54 \\
\hline Valor presente líquido, 6\% (R\$) & $9.576,98$ & $7.528,72$ & $8.150,25$ & $6.941,60$ \\
\hline Valor presente líquido, $10 \%$ (R\$) & $7.188,13$ & $5.189,10$ & $5.795,69$ & $4.616,09$ \\
\hline Valor presente líquido, $12 \%$ (R\$) & $6.003,32$ & $4.029,03$ & $4.628,11$ & $3.463,11$ \\
\hline
\end{tabular}

Os preços de concentrado e da cana-de-açúcar demonstrados anteriormente estão de acordo com a média histórica da região e são representativos para posteriores análises. Os valores de renda bruta por animal aumentaram quando se elevou o nível de concentrado da dieta. Isso pode ser facilmente explicado pelo aumento da produção de leite e também pela quantidade de fezes produzidas, uma vez que o esterco é um subproduto de grande importância na renda bruta, chegando a 15\%.

O valor do custo operacional efetivo (Tabela 9), que mostra quanto recurso está sendo desviado para cobertura de despesas, também elevou com o aumento do nível de concentrado na dieta, comprovando a importância da participação do custo de alimentação no total geral de custos, chegando a 63\% do custo total no maior nível de concentrado, além desta mesma fração de custo tornar-se cada vez mais importante, chegando a $88 \%$ do custo total. Smith (2003) descreve que o custo operacional não deve ultrapassar $65 \%$ da renda bruta e que esse índice é obtido apenas na dieta sem concentrado.

Em sistemas de produção intensiva, a alimentação costuma representar até $70 \%$ dos custos efetivos (não totais), mas, em propriedades menos tecnificadas, esses insumos respondem por menos de $50 \%$ dos custos. Desse modo, fica evidente que maiores investimentos na produção propiciam melhores resultados, com custos fixos diluídos (CEPEA, 2007). Os resultados encontrados no presente trabalho confirmam esta hipótese, com valores para esta proporção iguais a 42, 63, 67 e 70\% para as dietas contendo $0,16,24$ e $30 \%$ de concentrado.

Os valores de custo operacional total, que engloba a depreciação, apresentaram o mesmo comportamento do custo operacional efetivo, pois a mesma infraestrutura e animais foram utilizados em todos níveis de suplementação. O custo total por animal e por litro de leite produzido, que engloba a remuneração de capital (custo de oportunidade), cresceu à medida que aumentou o nível de concentrado na dieta.

Vale lembrar que outros aspectos poderiam interferir na viabilidade econômica da inclusão de concentrado na dieta, assim como a época de parição das vacas, a cota de leite e principalmente o volumoso utilizado, que deve ser observado com bastante cautela por técnicos e produtores. Um aspecto importante é que a inclusão de concentrado deve atender as exigências do animal.

Neste trabalho, os valores estiveram dentro dos propostos por Gomes (2001) para todos níveis de suplementação, lembrando que, neste caso, apenas a categoria vaca foi considerada.

Apesar de os parâmetros de produção serem favoráveis ao maior nível de concentrado, o lucro por animal foi menor para as dietas que continham concentrado e ainda menor para a dieta com o maior nível, fato que comprova ineficiência econômica da aplicação de concentrado na dieta de vacas leiteiras com estas produções e esta eficiência produtiva. Ressalta-se que, na variação de peso corporal por vaca (Tabela 8 ), os animais nas dietas com 0 e $16 \%$ de concentrado perderam peso. Esse fato pode ter acarretado problemas reprodutivos, que não foram avaliados neste trabalho, sendo, portanto, indicada a utilização de $24 \%$ de concentrado na dieta, pois, entre as dietas que continham concentrado, foi a mais interessante do ponto de vista econômico.

A taxa interna de retorno foi mais vantajosa quando não se utilizou concentrado na dieta (Tabela 10), demonstrando que este nível de suplementação é economicamente mais interessante para um investidor, gerando 1,94\% ao mês, enquanto na dieta com $30 \%$ de concentrado este valor reduziu para $1,54 \%$ ao mês.

O cálculo do valor presente líquido demonstra que este investimento é interessante para todas as taxas de desconto utilizadas, obtendo maior valor na dieta sem concentrado.

Vale insistir que, nas dietas com 0 e $16 \%$ de concentrado, houve diminuição do peso corporal dos animais, que não entra nos cálculos financeiros. Isso pode acarretar problemas reprodutivos, que podem inviabilizar o sistema de produção, sendo mais interessante a utilização de $24 \%$ de concentrado.

\section{Conclusões}

Apesar de os parâmetros de desempenho indicarem a utilização até 30\% de concentrado na dieta, os parâmetros econômicos comprovam que a utilização de concentrado, 
com o preço do quilo de leite igual a $\mathrm{R} \$ 0,70$ e a média do preço de concentrado igual a $\mathrm{R} \$ 0,50$, não é viável para vacas leiteiras mestiças. Além disso, o desempenho reprodutivo dos animais provavelmente seria prejudicado pela ausência de concentrado na dieta, devido à perda de peso dos animais, assim, é recomendável a utilização de $24 \%$ de concentrado na dieta.

\section{Referências}

CAPPELLE, E.R.; VALADARES FILHO, S.C.; SILVA, J.F.C. et al. Estimativas do valor energético a partir de características químicas e bromatológicas dos alimentos. Revista Brasileira de Zootecnia, v.30, n.6, p.1837-1856, 2001.

CEPEA - ESALQ/USP. Receita compensa gasto extra com dieta para rebanhos mais produtivos. Boletim Técnico, dez.2007. Disponível em: <www.cepea.esalq.usp.br/leite/boletim/162/ insumos.pdf $>$. Acesso em: 15/12/2007.

CONTADOR, C.R. Indicadores para seleção de projetos. In: CONTADOR, C. (Ed.) Avaliação social de projetos. 2.ed. São Paulo: Atlas, 1988. p.41-58.

CORDEIRO, C.F.A.; PEREIRA, M.L.A.; MENDONÇA, S.S. et al. Consumo e digestibilidade total dos nutrientes e produção e composição do leite de vacas alimentadas com teores crescentes de proteína bruta na dieta contendo cana-de-açúcar e concentrados. Revista Brasileira de Zootecnia, v.36, n.6, p.2118-2126, 2007.

COSTA, M.G.; CAMPOS, J.M.S.; VALADARES FILHO, S.C. Desempenho produtivo de vacas leiteiras alimentadas com diferentes proporções de cana-de-açúcar e concentrado ou silagem de milho na dieta. Revista Brasileira de Zootecnia, v.34, n.6, p.2437-2445, 2005 (supl.).

GOMES, S.T. Economia da ração na produção de leite. Jornal da Produção de Leite, v.13, n.143, p.1, 2001.

GOMES, S.T. Economia da produção leiteira. Belo Horizonte: Itambé, 2000. 132p.
MENDONÇA, S.S.; CAMPOS, J.M.S.; VALADARES FILHO, S.C. et al. Consumo, digestibilidade aparente, produção e composição do leite e variáveis ruminais em vacas leiteiras alimentadas com dietas à base de cana-de-açúcar. Revista Brasileira de Zootecnia, v.33, n.2, p.481-492, 2004.

MERTENS, D.R. Factors influencing feed intake in lactating cows: From theory to application using neutral detergent fiber. In: GA NUTRITION CONFERENCE, 46., 1985, Athens. Proceedings... Athens: University of Georgia. 1985. p.1-18.

NORONHA, J.F. Projetos agropecuários: administração financeira, orçamento e viabilidade econômica. 2.ed. São Paulo: Atlas, 1987. 269p.

NATIONAL RESEARCH COUNCIL - NRC. Nutrient requirements of dairy cattle. 7.ed. Washington, D.C.: National Academy Press, 2001. 381p.

OLIVEIRA, A.S.; VALADARES, R.F.D.; VALADARES FILHO, S.C. et al. Consumo, digestibilidade aparente, produção e composição do leite em vacas alimentadas com quatro níveis de compostos nitrogenados não protéicos. Revista Brasileira de Zootecnia, v.30, n.4, p.1358-1366, 2001.

PERES, A.A.C.; SOUZA, P.M.; MALDONADO, H. et al. Análise econômica de sistemas de produção a pasto para bovinos no município de Campos dos Goytacazes, RJ. Revista Brasileira de Zootecnia, v.33, n.6, p.1557-1563, 2004.

RIBEIRO JUNIOR, J.I. Análises Estatísticas no SAEG: Sistema de análises estatísticas. Viçosa, MG: UFV, 2001. 301p.

RODRIGUES FILHO, M.; MANCIO, A.B.; GOMES, S.T. et al. Avaliação econômica do confinamento de novilhos de origem leiteira, alimentados com diferentes níveis de concentrado e de cama de frango. Revista Brasileira de Zootecnia, v.31, n.5, p.2055-2069, 2002.

SILVA, D.J.; QUEIROZ, A.C. Análise de alimentos: métodos químicos e biológicos. 2.ed. Viçosa, MG: UFV, 2002. 165p.

SIMITH, T.R. Melhorando a lucratividade de fazendas leiteiras através do aumento na eficiência das operações. Sete Lagoas. In: CONGRESSO INTERNACIONAL REHAGRO, 1., 2003, Sete Lagoas. Anais... Sete Lagoas: 2003. 41p.

SKLAN, D.; ASHKENNAZI, R.; BRAUN, A. et al. Fatty acids, calcium soaps of fatty acids, and cottonseeds fed to high yielding cows. Journal of Dairy Science, v.75, n.9, p.2463-2472, 1992. 